\title{
Qual é o lugar da ficção na educação?
}

\section{What is the role of fiction in education?}

https://doi.org/10.34112/2317-0972a2017V35n69p25-35

Amanda Maurício Pereira Leite ${ }^{1}$

RESUMO: Elege-se a fotografia como elemento ficcional para aproximá-la da Educação. O movimento aqui descrito procura pensar a produção de visualidades (que se dá dentro e fora das instituições de ensino), na tentativa de reconhecer o potencial emancipatório pedagógico da imagem - neste caso, a fotografia. Para tanto, expõe-se o interesse sobre as interfaces entre Ficção e Educação, atenta-se ao que acontece no espaço da fronteira, do "entre", onde a fotografia é capaz de promover a e-ducação do olhar. Este exercício (descentralizado) articula o ver e o pensar. Entende-se que a emancipação do sujeito e a transformação do presente pode se dar na/pela ficção.

PALAVRAS-CHAVE: Fotografia; ficção; educação.

ABStRACt: Photography is chosen here as a fictional element to be approached in education. The movement described in this paper is an atempt to understand the production of visualities (produced inside and outside instituitions of education), trying to recognize the potential of the pedagogical emancipation of the image, in this case, photography. In order too do so, the interfaces between fiction and education are explored, focusing in what happens in the frontier space, the "in-between" space, where photography is capable of promoting the e-ducation of the eye. This (decentralized) exercise articulates seeing and

1. Universidade Federal do Tocantins, Palmas, TO, Brasil. 
thinking. The emancipation of the subject and the transformation of the present can take place in/through fiction.

KeYwords: Photography; fiction; education.

QUAL É O LUGAR DA FICÇÃO NA EDUCAÇÃO?

"Uma superfície não é simplesmente uma composição geométrica de linhas. É uma forma de partilha do sensivel"

(RANCIÈRE, 2009, p. 21)

"Interessa-me que uma página fuja por todos os lados, e no entanto que esteja bem fechada sobre si mesma, como um ovo"

(DELEUZE, 2013, p. 24)

A questão que abre esta reflexão é de fato instigante. Tentarei pensá-la a partir da articulação entre o campo educacional e os desafios que tangem a produção de visualidades por meio de fotografias. Não quero apenas provocar o modo como percebemos a relação entre Ficção e Educação, mas fazer pensar as conexões existentes entre elas e o que podemos produzir nesse encontro. Quando penso nas interfaces entre ficção e educação, gosto de abusar da força (educativa) da fronteira. Refiro-me ao pensar com a ficção e perceber que as imagens podem induzir o movimento do corpo e da mente num exercício de ver e pensar.

Rancière (2009, p. 13), em A partilha do sensivel, fala sobre a necessidade de compreendermos a "fusão da arte com a vida". Nesse sentido, identifica linhas de um pensamento das artes, "um modo de articulação entre maneiras de fazer, formas de visibilidade dessas maneiras de fazer e modos de pensabilidade de suas relações, implicando uma determinada ideia de efetividade de pensamento". Sua pesquisa se dedica a definir e observar sobre o que versa o regime estético das artes. Que conexões estabelecemos entre as imagens que vemos e os discursos que tecem a vida?

Os movimentos de vanguarda, suas imagens e discursos nos evocam a refletir sobre a estética e os dilemas intelectuais contemporâneos. $\mathrm{O}$ uso da fotografia, por exemplo, é evidente. Praticamente fotografamos e vemos fotografias todos os dias. Narrativas visuais são produzidas e publicadas nas redes sociais num frenesi efervescente. Crianças, jovens e adultos (muitos inseridos em contextos educacionais) narram diversas histórias sobre si mesmos. 
Mas o que essas narrativas revelam? Que relações travam com o olhar do espectador? Seria um tipo de imagem politizada que se posiciona esteticamente sobre a vida ou composições ficcionais daquilo que se deseja ser? Se na contemporaneidade o uso da fotografia se dá dentro de um movimento cultural reconhecido como "cultura visual", como problematizar então o uso intenso da fotografia em nosso cotidiano, especialmente nos processos de ensino?

Ao pensar nos sujeitos que habitam o campo da Educação, vemos a coexistência de gerações em um mesmo espaço. Dentro de uma sala de aula estão crianças, jovens e adultos de diferentes contextos culturais. Estudantes e professores que expõem suas diferenças sobre os modos de viver e perceber o mundo. Na sala de aula (virtual ou presencial), esses sujeitos (por meio da fotografia) narram acontecimentos, expõem desejos, dizem de si. Daí hoje pensarmos a Educação por outras vias. E, no caso da fotografia, desassossegar o olhar para perder-se. Perder-se num movimento que difere da classificação ou do julgamento entre "certo" e "errado", que não está voltado à finalidade do uso da imagem fotográfica em sala de aula, ao contrário, toma a fotografia como atravessamento, força latente, imagem pensante.

Parece-me que a Educação, mesmo que atravessada pelo uso das mídias e pela velocidade de informações que lhe chegam, ainda lida com a imagem como uma espécie de representação da realidade. Os livros didáticos, as colagens nos cartazes, as campanhas nos corredores, os trabalhos produzidos com imagens (filmadas ou fotografadas) geralmente representam a vida real. (Um tipo de disciplinamento do olhar em torno do que tornamos visível e dizível?) Salvo algumas exceções, parece não haver espaço para outra leitura senão aquela utilitarista ou ilustrativa da imagem, que exibe a sociedade e seus conflitos numa espécie de retrato real de verdades e fatos.

Esse tipo de abordagem emana dos modos como a televisão e as mídias expõem as narrativas visuais; ou revela uma carência, no processo de formação do professor, que o conduz a trabalhar com perspectivas menos representativas. Para Rancière (2009, p. 55), "a ficcionalidade própria da era estética se desdobra entre dois polos: entre a potência de significação inerente às coisas mudas e a potencialização dos discursos e dos níveis de significação". Por isso, restringir leituras e não possibilitar que a ficção habite o campo educacional é improdutivo demais para a nossa formação, que dirá para a e-ducação do olhar, como pontua Jan Masschelein (2008).

Se somente propusermos a conexão entre a fotografia e o registro da vida (recortes de histórias e conflitos humanos), nos afastaremos de outras abordagens e problematizações. Assim, a fotografia continuará reforçando estereótipos (e um 
uso utilitário). Como pensar, então, a imagem como dispositivo educativo para a proposição de uma Pedagogia da imagem?

A fotografia sugere a inversão de perspectivas, a construção ficcional de narrativas. Realidades são inventadas e dispostas ao olhar curioso que confunde, nega, afirma, questiona e embaralha aquilo que vê. A arte fotográfica ficcionaliza verdades, por isso é complexa. Entre recortes temporais e espaciais, entre coisas que são visíveis e dizíveis e aquelas que não conseguimos ver ou dizer, podemos propor novas relações entre realidade e ficção. Num jogo experimental de formas, palavras e ruídos, podemos compor aquilo que Rancière (2009, p. 17) denomina como "práticas estéticas" ou "visibilidade das práticas estéticas da arte, do lugar que ocupam, do que fazem, no que diz respeito ao comum".

Aqui não vou elencar temas que podem ou não ser trabalhados na Educação, mas desconfiar de abordagens que tomem a fotografia tão somente como documento real. Quero observar que tipos de discursos e enunciados têm sido produzidos sobre a/a partir da/ com a fotografia (e a ficção), relacionados à formação de educadores. "Os enunciados políticos ou literários fazem efeito no real. Definem modelos de palavra ou de ação, mas também regimes de intensidade sensível. Traçam mapas do visível, trajetórias entre o visível e o dizível, relações entre modos de ser, modos de fazer e modos de dizer" (RANCIÈRE, 2009, p. 59). Por isso questiono: qual é o lugar da Ficção na Educação? Há espaço para a ficção nos processos de formação? A Educação se interessa pela Fiç̧ão?

Muitas vezes a ficção não passa de um elemento secundário ou complementar de um conteúdo trabalhado em sala de aula. Isso significa que as imagens, especialmente as fotográficas, ainda são usadas como uma espécie de "pedagogia do transporte", em que uma mensagem deve ser transmitida, como pontua Jacquinot (1977, p. 16). Trata-se de uma imagem interpretada, que conduz e orienta o olhar do espectador. Narra-se algo, mas não se permite que o espectador perceba por ele mesmo os detalhes da narrativa. A "ficção educativa" (se assim podemos dizer) parece ser usada nos processos de ensino com intento pedagogizante ou didático. Há pouco estímulo para que o espectador avance a fronteira da representação para pensar a linguagem ficcional. A noção de Pedagogia da imagem que defendo aqui não é explicativa; ao invés disso, cria condições para que o leitor interaja com a fotografia a partir de suas memórias, sensações, atravessamentos... que ele crie a sua própria narrativa, sem ser direcionado. 
Por outro lado, acreditamos estar inovando quando solicitamos a um estudante que fotografe e exponha um determinado conhecimento/conceito nas aulas, mas, quando olhamos para as fotos produzidas por ele, elas estão esvaziadas de conteúdo. (Estaríamos diante de uma proposta pedagógica frágil?) Embora a educação se aproprie da fotografia e a coloque em cena para realizar alguns exercícios, é preciso fazer mais. Significa estudar profundamente a potencialidade da imagem, para, então, propor e experimentar novas formas de aprender/pensar. A imagem, o modo como ela é produzida e apresentada, pode estimular processos cognitivos.

A ficção provoca rupturas pela própria forma. A forma também é conteúdo. Ela pode ser didática (quando visa informar, ensinar ou conscientizar alguém), mas a experiência do sujeito, não. Se o uso da imagem ficcional na educação for criativo e sugerir um estilo singular para o ver e o pensar, então, poderemos perceber que o viés pedagógico é interno e está localizado na própria imagem, em seu "plano de imanência”, para lembrar Deleuze e Guattari (1992, p. 51). Isso nos afasta de qualquer discurso externo ou da intencionalidade pedagogizante daquele que se apropria da imagem (aqui penso na figura do professor). A imagem produz conhecimento e ensina a pensar, desde que não seja submetida a um método pedagógico.

Se estamos sujeitos cotidianamente a ver imagens (exibidas nos diversos meios de comunicação), falta-nos tempo para refletir sobre elas e, ainda, aprender mais a propósito de sua produção. Por isso, penso que a educação, ao propor qualquer tipo de trabalho com imagens, pode se esforçar para fazer uma abordagem mais pausada, que se diferencie das imagens comerciais. Minha expectativa é de que a educação produza imagens, considere o tempo de cada produção, pense sobre a produção, perceba distintos saberes e se relacione com eles. Eis aí uma proposta de Pedagogia da (própria) imagem.

A ficção - e, neste caso, a fotografia - pode ensinar quando expõe na forma e no conteúdo artifícios que induzem o espectador (estudante e professor) a pensar. Pensar tem ligação com um processo quase artesanal que admite cada uma dessas etapas e é capaz de transformar a realidade (e por que não modificar o contexto educacional e seus métodos didático-pedagógicos?).

Para realizar uma captura, o fotógrafo traça um planejamento. Ainda que decida sair em busca de instantâneos, ele escolhe o tema, a narrativa, o enquadramento, a cor... Há, sem dúvida, preferências por perspectivas que irão emoldurar a cena e o olhar do espectador. O gesto do fotógrafo crava a aparência das coisas na película sensível, mas uma aparência registrada a seu modo, pelo recorte de suas lentes. $\mathrm{O}$ 
fotógrafo cria, recria, inventa, compõe ficções. As ficções podem até se aproximar do real, mas não deixam de ser ficcionais.

Assim como um texto que, ao ser publicado, perde a referência do autor (no sentido posto por Barthes (2004) em A morte do autor), a fotografia, ainda que publicada como produto final, está sempre aberta, à espera de leituras, conexões, (des)continuidades relacionadas ao cotidiano do espectador. Isso nos possibilita acessar o espaço das fronteiras. Nem isso, nem aquilo. $\mathrm{O}$ convite está justamente nas interfaces entre realidade e ficção ou, mais precisamente, no encontro da ficção com a educação. Como podemos então liberar a nossa visão?

Se o "real precisa ser ficcionado", como afirma Rancière (2009, p. 58), coloco em debate a "razão da ficção" na formação de professores e na educação. Com isso não pretendo rotular dois universos ou esferas distintas (realidade X ficção); ao contrário, quero, a partir da mistura, deslocar o olhar, buscar outros modos de perceber e lidar com a imagem ou, ainda, novas estratégias de aprendizagens que perpassem a arte, a estética, a e-ducação do olhar.

Permitir que a ficção teça processos educativos significa criar fissuras, lidar com o inesperado, fruir entre conteúdos e sensações, procurar pelo dado novo (dentro e fora da imagem), revelar aos olhos aquilo que não se vê. Um movimento marginal. A ficção pode gerar um atravessamento singular no sujeito. Nesse sentido, o trabalho com imagens na educação, especialmente com fotografias, permite não apenas pensar as relações entre realidade e ficção, fotografia e conhecimento, mas também produzir saberes a partir da imagem ficcional.

A experiência com a arte oportuniza ler a fotografia por inúmeras vias. Ler a imagem para fora de si, dialogar sobre ela, estabelecer relações com diferentes conceitos. Uma leitura que não necessariamente precisa ser orientada, mas aberta. Para Rancière (2009, p. 59), "a política e a arte, tanto quanto os saberes, constroem 'ficções', isto é, rearranjos materiais dos signos e das imagens, das relações entre o que se vê e o que se diz, entre o que se faz e o que se pode fazer".

Quando operamos por imagens, entramos em contato com experiências e experimentos estéticos. A partir deles estabelecemos conexões entre as fotografias que vemos e as imagens que trazemos em nós. Toda narrativa visual perpassa certa discursividade. Aproximamos a fotografia da realidade em que vivemos (ou imaginamos). Podemos nos sensibilizar, ver e ser vistos, propagar fatos, trocar ideias, nos conscientizar, manifestar a nossa subjetividade e agenciar a formação estética a partir da/para com a imagem fotográfica. 
Por isso insisto que a ficção seja pensada dentro dos processos de ensino. Não se trata de restringir a imagem a um lugar cativo dentro da educação (uma disciplina, por exemplo); ao contrário, é interessante aproximar os conteúdos e as ações educacionais da produção de visualidades que marcam o nosso tempo. Se as imagens cruzam o nosso cotidiano (nas escolas e fora delas), podemos estudá-las para potencializar nossas aprendizagens diante da complexidade das narrativas visuais.

Somos espectadores e produtores de imagens (tudo ao mesmo tempo). Narramos, habitamos capturas, marcamos o que está dentro e fora da cena, procuramos pelo (in)visível $d a / n a$ imagem (presença/ausência). Pensar sobre a formação estética é também buscar diálogos com diferentes teorias que pensem a própria produção de imagens. (E isto já não seria ficção?) Talvez uma revolução estética, como pontua Rancière (2009, p. 54): "a revolução estética redistribui o jogo tornando solidárias duas coisas: a indefinição das fronteiras entre a razão dos fatos e a razão das ficções e o novo modo de racionalidade da ciência histórica”. E ainda:

[...] a revolução estética transforma radicalmente as coisas: o testemunho e a ficção pertencem a um mesmo regime de sentido. De um lado, o "empírico" traz as marcas do verdadeiro sob a forma de rastros e vestígios. "O que sucedeu" remete pois diretamente a um regime de verdade, um regime de mostração de sua própria necessidade. Do outro, “o que poderia suceder” não tem mais a forma autônoma e linear da ordenação de ações (RANCIÈRE, 2009, p. 57).

Ao inserir a fotografia nos processos de formação, e mais, ao abrir espaço para a ficção na educação, podemos propor uma quebra na rotina, no ritmo ao qual nossos corpos e mentes já estão acostumados. Uma ruptura para outras reflexões. Não se trata de buscar "o sentido" ou "o que o autor quis dizer", ou ainda a "mensagem que a obra quis passar", mas de provocar um movimento formativo revolucionário, como Rancière (2009) anuncia.

Diga-me: por que é tão difícil para a educação deixar de explicar?

Parece que, nos processos de ensino, se as coisas não forem esgotadas no sentido elucidativo, elas não podem acontecer. A ficção não consegue entrar na educação sem ser explicada. É quase impossível que a ficção penetre os processos de ensino, sem antes decifrar todos os seus mistérios, as mensagens subliminares, os enigmas das obras ficcionais. Esse movimento tão óbvio e tradicional, que desde o início põe o espectador numa espécie de jogo de intérprete, em que assimilar e 
estabelecer vínculos entre a vida real e a obra ficcional sempre foi um imperativo, pouco problematizado.

Se a imagem propõe metáforas, cria vazios, sugere o encontro de temporalidades e espacialidades distintas, por que a educação condiciona a relação entre o espectador e a imagem? Evidente que, enquanto educadores, podemos orientar nossos estudantes a realizar leituras de certas imagens (esta é inclusive uma possibilidade da e-ducação do olhar); no entanto, é igualmente importante aceitar que, muitas vezes, não há o que se explicar. Apenas sentir, permitir se envolver pelos olhos, entregar-se a sensações que não dizem e, quem sabe, ultrapassar o modo habitual com que lidamos com as imagens.

Não importa constatar o real em imagens ficcionais, mas fugir de qualquer fim aplicativo/utilitário da arte na escola, na educação. O movimento que defendo passa longe de uma didatização da fiçcão (ou do uso de imagens). Meu interesse (quase em tom de manifesto) sugere que "descondicionemos" o olhar de legendas explicativas ou aplicáveis. E aqui retorno ao "convite livre ao olhar" apontado por Sontag (2003, p. 73) no texto: Diante da dor do outro.

As escolas e as universidades organizam sistematicamente os saberes que os estudantes deverão obter ao longo de sua formação. De alguma forma, essas instituições privilegiam certos pontos de vista em relação a outros. Oferecem imagens e arquétipos de aprendizagens. Como não pensar então que elas também intervêm no modo como esteticamente somos formados ou no modo como vemos? Até que ponto elas educam o nosso olhar?

Embora a censura nos dias atuais pareça menor ou mais contida nos processos educativos, não significa que a imagem tenha deixado de ser marginal. Ainda impomos limites e condições aos atravessamentos que podem se dar pela imagem. Restringimos o prazer do olhar, as sensações, as surpresas.... Acostumamo-nos a esperar que em uma atividade pedagógica apareça a reflexão, a crítica, as impressões, e não as emoções do leitor. A mente vem primeiro que o corpo. Mas quem provoca esse distanciamento?

Se a aposta educativa das instituições é transformar o estudante em um espectador crítico, não é dominando (pedagogicamente) o olhar do Outro que essa mudança acontecerá. (Aliás, não seria atrevido demais acreditar que o pensamento do Outro pode ser direcionado?) Ver criticamente não significa esquadrinhar a imagem em busca daquilo que o Outro não vê. Não é um movimento de vasculhar algo para emitir opinião. É um atravessamento que acontece nas linhas de fuga. 
Algumas imagens conseguem impactar o olhar do espectador rapidamente. Às vezes, impressionam mais do que as palavras. Por isso, não é difícil encontrar estratégias de ensino que usam as imagens para ganhar a atenção dos estudantes. Mas, ao propor uma $e$-ducação do olhar, não podemos deixar de questionar se essa prática limita e (ainda que não deseje) acaba por "domesticar" o olhar e/ou o pensamento do espectador. Então, que outras abordagens seriam possíveis?

Se nos colocarmos numa relação aberta com a ficção e com o uso das imagens nos processos educativos, podemos trabalhar com a concepção do inacabado. Significa pensar sobre os conflitos humanos, por exemplo, a partir de imagens ficcionais, sem ter que responder de imediato às questões que surgem delas. Este tipo de pedagogia ou prática pedagógica investiga, espera, dá tempo e atenção aos atravessamentos que se dão pelo olhar. Somos conscientes de que a imagem é enigmática e, por sua natureza porosa, não pode ser associada a uma única perspectiva.

O diálogo sobre a ficção é pertinente e fundamental para a nossa formação estética. Narrativas ficcionais podem se inspirar e se aproximar de contextos reais, porém, serão sempre criações com características próprias, com personagens e mundos inventados. Invenções capazes de nos fazer pensar sobre nós mesmos e sobre a nossa relação com o Outro.

Quando penso mais precisamente no caso de uma escola ou de uma universidade, não sugiro criar uma cadeira específica em que o trabalho com a fiç̧ão aconteça (em um lugar marcado). O que proponho é desfazer velhos hábitos para que a ficção transite livremente pelos espaços formativos e pela nossa formação. De modo que saiamos da comodidade rumo a uma espécie de utopia, que, para Rancière (2009, p. 61), seria "o não-lugar, o ponto extremo de uma reconfiguração polêmica do sensível, que rompe com as categorias da evidência”.

São aspirações desta jovem pesquisadora, professora e fotógrafa em relação ao que acontece nas salas de aula. Enquanto professora, desenho (e desejo) uma proposta que traga a narrativa ficcional para a constituição do sujeito, entendendo que o espaço de fronteira é tão importante quanto a justaposição da realidade. A ficção pode ajudar o sujeito a refletir sobre a ética de si e o domínio do ser consigo, além de buscar compreender melhor o mundo em que vive e o tempo presente.

Observo que diferentes saberes se dão no cruzamento entre a ficção e a educação, mesmo que para alguns isso pareça contraditório. Para Rancière (2009, p. 53): 
[...] a separação da ideia de ficção da ideia de mentira define a especificidade do regime de representação [...] é um jogo de saber que se dá num espaço-tempo determinado. Fingir não é propor engodos, porém elaborar estruturas inteligíveis-

Assim, a produção desses saberes acontece por diferentes meios e contaminações. Daí a possibilidade de lidarmos com saberes abertos, até mesmo experimentais, cujo objeto está na fronteira. O sentido pode estar na linha de fuga entre aquilo que se põe vivível e aquilo que ainda não vemos. A própria fronteira é feita de diferenças, por isso desloca, nos faz tomar a fotografia e insistentemente transitar entre o ver e o pensar.

A fotografia nos desafia a ver, ver não necessariamente o que está exposto na imagem, mas o cheiro, o som, o silêncio, a música, a poesia... A fotografia pede atenção a sua história e a sua complexidade. Uma imersão no avesso das coisas. Não o avesso da margem, mas o avesso de convenções e perspectivas. Ou, quem sabe ainda, buscar na fotografia o aperspectivismo e a recusa da representação do real. No aperspectivismo a fotografia seria um fenômeno de "desrealização" que envolve a recusa de copiar a realidade ou fazer o útil se realizar. Tal negação se expressa não apenas mimeticamente, mas também por meio de alterações nas estruturas. Isso ocorre quando a fotografia extrapola a moldura em que se inscreve.

Se houvesse uma fórmula especial ou um didaticário (para lembrar o termo de Sandra Corazza [2012]) sobre como trabalhar com imagens na Educação, talvez fosse possível listar ações que orientassem o professor ao longo de uma aula. Contudo, não existem fórmulas! Importa ao professor experimentar! Viver a experiência de uma aula a seu modo, errando e acertando todos os dias. Investigando profundamente o seu cotidiano.

A docência (da diferença) é criadora e não transmissora. Assim, o professor tem a possibilidade de romper com a passividade e produzir a diferença, $\mathrm{o}$ acontecimental, quando cria e ministra sua aula. Cria ficções (com base na vida), cria sentidos. O professor pode inventar novas didáticas e transformar conteúdos conhecidos em outras coisas, pode estimular que o "rasgo no guarda-chuva" aconteça para tornar algo potente, como sugere Deleuze e Guattari (1992). O rasgo no senso comum, no cotidiano da aula, permite que o caos apareça e nos leve a pensar, a (re)ver a sutileza das coisas, em um movimento que abre portas e possibilidades.

É na criação das aulas e/ou no jeito como as propomos que reside o prazer do professor/pesquisador. Em uma aula tudo pode ser útil, sem ser utilitário, inclusive a 
fotografia. Tecer uma educação mais experimental, que se concentre em ver e pensar a fotografia e a ficção por vias mais livres e não "escolarizantes" é um convite aberto a qualquer educador(a). O desejo que segue latente é o de proliferar a ficção no universo das aulas. Habitamos o prazer quando criamos na Educação. Quando mergulhamos nesses processos, maquinamos a Educação. Experimentamos um prazer aventureiro, que acredita na potência humana. Somos capazes e temos uma potência criadora!

\section{REFERÊNCIAS}

BARTHES, Roland. O rumor da língua. Tradução de Mario Laranjeira com revisão de Andréia Moisés. São Paulo: Martins Fontes, 2004.

CORAZZA, Sandra Mara. Didaticário de criação: aula cheia, antes da aula. In: ENCONTRO NACIONAL

DE DIDÁTICA E PRÁTICAS DE ENSINO - ENDIPE, 16., 2012, Unicamp, Campinas.

DELEUZE, Gilles. Conversações. Tradução de Peter Paul Pelbart. São Paulo: Editora 34, 2013.

DELEUZE, Gilles; GUATTARI, Félix. O que é a filosofia. Tradução de Bento Prado Junior e Alberto

Alonzo Muñoz. Rio de Janeiro: Editora 34, 1992.

JACQUINOT-DELAUNAY, Geneviève. Imagem e Pedagogia. Mangualde: Edições Pedago, 2006a.

Tradução e Revisão Científica por Lia Oliveira. Original: Jacquinot, G. Image et Pédagogie.

Paris: PUF, 1977.

MASSCHELIEN, Jan. E-ducando o olhar; a necessidade de uma pedagogia pobre. Educação \& Realidade, v. 33, n. 1, p. 35-48, 2008.

RANCIÈRE, Jacques. A partilha do sensivel: estética e política. Tradução de Monica Costa Netto. São Paulo: EIXO experimental org.; Editora 34, 2009.

SONTAG, Susan. Diante da dor dos outros. Tradução Rubens Figueiredo. Rio de Janeiro: Companhia das Letras, 2003 .

\section{SOBRE A AUTORA}

Amanda Maurício Pereira Leite é Fotógrafa, pedagoga, Doutora e Mestre em Educação pela Universidade Federal de Santa Catarina. É Professora na Universidade Federal do Tocantins (UFT).

Site: http://amandampleite.wixsite.com/amandaleite

Recebido em 11 de novembro de 2016 e aprovado em o7 de fevereiro de 2017. 